\title{
ON KY FAN'S INEQUALITY AND ITS ADDITIVE ANALOGUES
}

\section{J. ROOIN}

Abstract. In this paper we give a discrete proof of Ky Fan's inequality. Also, we extend the additive analogues of Ky Fan's inequality to a very general case and give some applications.

Mathematics subject classification (2000): 26D15.

Key words and phrases: Inequality, Ky Fan's inequality, mean value theorems, convexity.

\section{REFERENCES}

[1] H. ALzer, Inequalities for arithmetic, geometric and harmonic means, Bull. London Math. Soc., 22 (1990), 362-366.

[2] H. AlZER, Refinements of Ky Fan's inequality, Proc. Amer. Math. Soc., 117 (1993), 159-165.

[3] H. Alzer, The inequality of Ky Fan and related results, Acta Appl. Math., 38 (1995), 305-354.

[4] H. Alzer, Ungleichungen für geometrische und arithmetische Mittelwerte, Proc. Kon. Nederl. Akad. Wetensch., 91 (1988), 365-374.

[5] E. F. BECKENBACH AND R. BELlman, Inequalities, Springer-Verlag, Berlin, 1961.

[6] A. Dinghas, Some identities between arithmetic means and the other elementary symmetric functions of $n$ numbers, Math. Ann., 120 (1948), 154-157.

[7] I. GaVReA AND T. TRIF, On Ky Fan's inequality, Math. Inequal. Appl., 4 (2001), 223-230.

[8] A. MCD. MERCER, A short proof of Ky Fan's arithmetic-geometric inequality, J. Math. Anal. Appl., 204 (1996), 940-943.

[9] J. E. PeČArIĆ AND H. Alzer, On Ky Fan's inequality, Math. Panonica, 6 (1995), 85-93.

[10] J. SÁNDOR AND T. TRIF, A new refinement of the Ky Fan inequality, Math. Inequal. Appl., 2 (1999), $529-533$. 